4

\title{
Cutting edge control by monitoring the tapping torque of new and resharpened tapping tools in Inconel 718
}

\author{
R. Polvorosa ${ }^{1} \cdot$ L.N. López de Lacalle ${ }^{1} \cdot$ Antonio J. Sánchez Egea $^{2} \cdot$ A. Fernandez ${ }^{1} \cdot$ M. Esparta $^{3} \cdot$ I. Zamakona $^{3}$ \\ Received: 13 September 2019 / Accepted: 30 December 2019 \\ (C) Springer-Verlag London Ltd., part of Springer Nature 2020
}

\begin{abstract}
In aerospace industry, tapping is the prime choice for hole threading in jet aero-engine turbine components. Taps are not usually resharpened, unlike other tools which indeed are resharpened once they have accomplished a certain number of cycles of service. Instead, cutting taps are discarded when they reach a certain number of threaded holes. The waste of cutting tools and the timing for tool replacement is computed in the cost expenses of the end part. In order to reduce manufacturing waste, this work focuses on studying different tapping configurations, to prove the feasibility of resharpening in the interest of extending the tap's service life. Tapping experiments are performed in Inconel 718 under several conditions: (a) resharpened taps, (b) resharpened and recoated taps, (c) an additional $2^{\circ}$ chamfer clearance angle taps and (d) as-received taps (baseline). The results show that the three-time resharpened taps increased their lifespan up to 200\%. Tap's performance is analyzed considering several criteria: checking by Go/No-Go gauges, evaluating the flaking or notching of cutting edges, measuring axial forces and torques, and analyzing the surface integrity of the threaded holes. Therefore, monitoring the cutting forces and torque during tapping helps us to anticipate to the tool's fracture; and controlling the crest edge roundness progression is crucial for having an accurate thread tolerance and the desired surface integrity.
\end{abstract}

Keywords Inconel $718 \cdot$ Tapping $\cdot$ Monitoring $\cdot$ Tapping torque $\cdot$ Surface integrity

\section{Introduction}

In the aeronautic industry, the production of threaded holes is a common operation which allows to assembly different components. Besides, tapping is considered a critical operation since it is one of the latest operations to perform in the production chain, which implies a high added value to the aeronautic component. For this reason, the selection of tapping conditions tends to be quite conservative, in order to avoid unacceptable threads or broken taps stuck in the holes, which would involve undesired procedures, such as tap removing

Antonio J. Sánchez Egea

antonio.egea@upc.edu

Department of Mechanical Engineering, Faculty of Engineering of Bilbao, University of the Basque Country, Alameda de Urquijo s/n, 48013 Bilbao, Spain

2 Department of Mechanical Engineering, Universitat Politècnica de Catalunya, Av. Eduard Maristany, 16, 08019 Barcelona, Spain

3 ITP Aero S.A., Parque Tecnológico n 300, 48170 Zamudio, Spain and reparation of surface damages, of a nearly finished component. Additionally, the surface integrity requirements in the aeronautics sector have extreme importance involving really tight tolerances compared to other industry sectors, like automotive or energy. It is a common practice to demand an exhaustive control of the tools which have been used along all the number of cycles of service, and it is not unusual to perform an in situ monitoring of the power consumption of the machine-tool interaction. Power consumption is a reliable indicator of the tool wear for drills, mills, taps, or reamers. Aeroengine materials are known to dispose high strength and work-hardening characteristics and, consequently, a low machinability. This affects the cutting tool efficiency on its service life. One of the most commonly used aeronautics materials is Inconel 718, which is a precipitation hardening nickelbased superalloy. This kind of alloy is used in the hot stages of jet engines and turbines of power plants, because of its high strength and corrosion resistance at extreme temperatures.

During machining operations, tool damage can be attributed either to a high spindle power consumption or thermal effects that originated a gradual failure of the cutting tool. Accordingly, the worn cutting tool must be resharpened to 
obtain new cutting edges, which allow us to perform another cycle of service. In aerospace industry, tool resharpening process is quite used in tools like drills [1], mills [2, 3], discs [4], or reamers [5], but it is not so spread when it comes to cutting taps. Cutting taps are discarded after performing several rounds of threads, which depend on the diameter, material of the workpiece, or even tap's material itself while considering a conservative criterion. Unlike for machining, drills, or mills, few works can be found involving tapping with resharpened tools. One of these works was reported by Armarego et al. [6], where tapping capabilities in carbon steels and stainless steels were investigated. In addition, many of these cutting tools present protective layers of coating to improve their mechanical properties. In particular, tapping and other cutting tools, like drills or mills, have a single or multiple coating layers to reduce the friction forces and tool wear [7]. Physical vapor deposition (PVD) coatings are widely spread, among them the most used in industrial coatings are TiCN, TiN, or TiAlN. For example, Reiter et al. [8] investigated the cutting capabilities of these protective layers. The authors concluded that the application of TiCN coating had an excellent abrasive and adhesive wear resistance during blind hole tapping in austenitic stainless steel.

In this investigation, tapping experiments are performed in Inconel 718 with high speed steel (HSS) taps coated with a single layer of TiCN. Afterwards, the cutting capabilities are compared between as-received taps (reference), resharpened taps, modified chamfer relief taps, and resharpened and recoated taps. All these taps are right-hand spiral type with a spiral point for threading blind holes. They also have a small chamfer relief angle to shear off the chip root, rotating them in reverse to take them out of the hole, although a greater chamfer relief angle was tested to determine its influence in the cutting forces. Therefore, tool wear, cutting forces, tapping torque, and surface integrity are analyzed after accomplishing from 1 to 8 threaded holes in Inconel 718, in order to compare tapping performance for all the aforementioned tap configurations.

\section{Methodology}

\subsection{Experimental setup}

A commercial Inconel 718 (50-55 wt\% Ni, 17-21 wt\% Cr, 4.75-5.5 wt $\%$ Nb, 2.8-3.3 wt\% Mo, 0.65-1.15 wt\% Ti, 0.2$0.8 \mathrm{wt} \% \mathrm{Al}$ and balance $\mathrm{Fe}$ ), common in aircraft engines, was used in this research. The main mechanical properties of Inconel 718 are listed in Table 1. This alloy was characterized by great mechanical performance and corrosion resistance, which maintain its properties even at high operating temperatures. It is also widely denominated as a hard-to-cut material, due to its low machinability. Figure 1 shows the experimental
Table 1 Overall mechanical properties and material hardness of tested Inconel 718

Inconel 718

Inconel 718

Density $8.19 \mathrm{~g} / \mathrm{cc}$

Tensile strength $\left(20^{\circ} \mathrm{C}\right)$

$1375 \mathrm{MPa}$

Tensile strength $\left(650^{\circ} \mathrm{C}\right)$

$1100 \mathrm{MPa}$

Young's modulus

Elongation $\left(20^{\circ} \mathrm{C}\right)$

Elongation $\left(650^{\circ} \mathrm{C}\right)$

$200 \mathrm{GPa}$

tests of drilling and tapping that were carried out in a 3-axis moving table vertical machining center, model: Kondia A6.

The strategy which was adopted for making threads consisted of the following steps: drilling, countersinking, redrilling, and, finally, tapping. In particular, the first drilling operation was performed with tungsten carbide drills up to a depth of cut of $14.2 \mathrm{~mm}$ and a diameter of $4.5 \mathrm{~mm}$. External coolant system was used to fill blind holes with crude oil, and, after that, the holes were blown with compressed air to remove the metal debris from drilling. Then, a countersinking operation was performed with a tungsten carbide tool with a diameter of $6.1 \mathrm{~mm}$ and a chamfer angle of $120^{\circ}$. Later, a redrilling operation was carried out with a tungsten carbide end-mill tool with a diameter of $5.1 \mathrm{~mm}$ to thread the optimal geometrical dimensions of the holes. A maximum of five holes were done with the end-mill tool to avoid wear. In this case, the fracture failures were reduced, and the thickness of the heat affected layer in the redrilling was lower than in the first drilling operation, because of a lower friction at the material-tool interfaces. Consequently, this smaller friction coefficient affected the cutting force, tapping torque, and the surface integrity, as described in the result section. Finally, the last step in the process was the tapping operation with a plug tap reference EG UNF 10-32, Tolerance 3B, and a diameter of 0.2306 in (ref. ID 148008 at DC SWISS SA). The material of the tap contains $8 \%$ of cobalt, which enhances such mechanical properties, as strength, toughness, and wear resistance. Different tap configurations were tested in this superalloy, particularly geometrical modifications, coating layer, and resharpening operations were modified to analyze their impact on tapping. Table 2 exhibits the main characteristics of the tested taps and the number of tap configurations used. Table 3 presents the operational conditions for the threading process.

The cutting performance of the resharpened taps were evaluated by taking into account several aspects: checking of the threaded holes using the Go/No-Go gauge, recording the cutting forces, counting the number of broken cutting edges as a consequence of threading, and observing the surface integrity. Additionally, the following considerations were taken into 
Fig. 1 Tapping setup in a 3-axis machining center, hole strategy, and the final workpiece

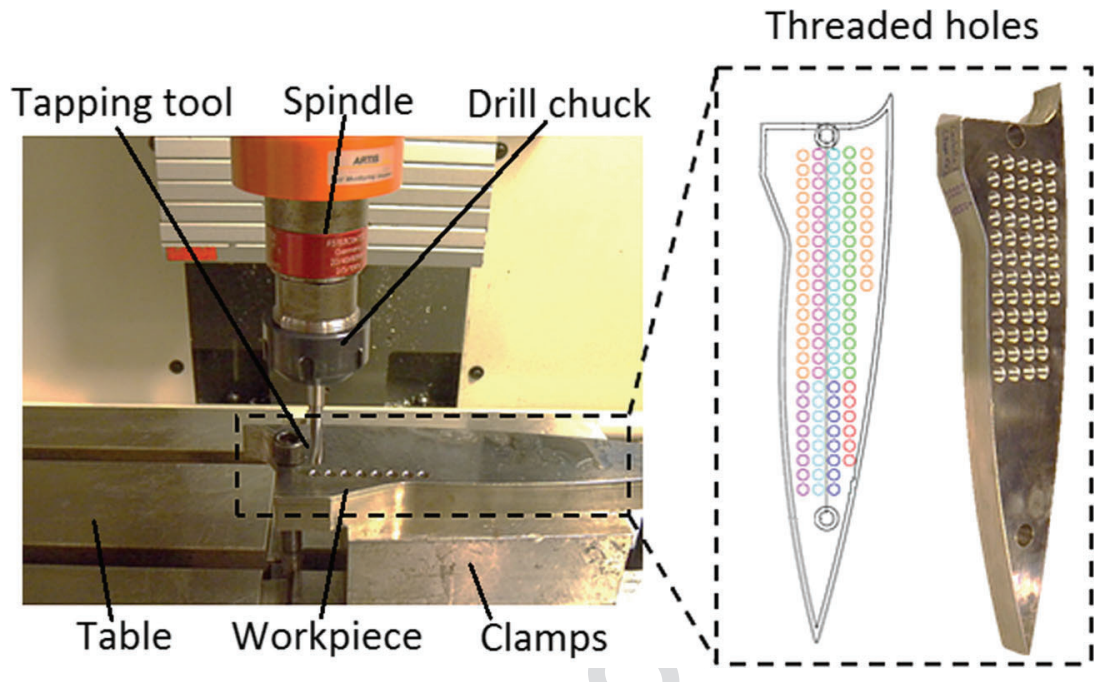

t2.9 $\mathrm{N}^{\circ}$ of as-received taps tested

t2.10 $\mathrm{N}^{\circ}$ of once resharpened taps tested

t2.11 $\mathrm{N}^{\circ}$ of three times resharpened taps tested

t2.12 $\mathrm{N}^{\circ}$ of resharpened and recoated taps tested

t2.13 $\mathrm{N}^{\circ}$ of additional 2 chamfer clearance angle taps tested

t2.14 Total of taps tested

t2.15 $\mathrm{N}^{\circ}$ threaded holes performed per tap
$5.86 \mathrm{~mm}$

Plug tap

UNF-3B

HSS-E-PM

$\mathrm{TiCN}$

$3 \mathrm{~B}$

2

14

4

1

2

23

8

\subsection{Resharpening process}

The completion of resharpening depends on the employee's experience, where the outer peak of the cutting edges and the nominal flute diameter play a key role to perform an accurate tapping operation. These cutting edges of the tap are responsible for removing material, where the rake angle, chamfer length, and relief angle, as well as the number of lands are important parameters to take into account during tapping [6]. In this work, $\mathrm{C}$ spiral-flute taps with three cutting lands involved in thread formation were investigated, as shown in Fig. 2a. The tool wear was the main reason to carry out a resharpened process of a worn cutting tap. The steps to resharpening a worn tool are the following ones: the first step consisted in cutting the initial part of the chamfer length, as shown in Fig. 2b. The second step consisted in making a tap chamfer regeneration, defining a longer and sharper chamfer of the thread, as described in Fig. 2c. In this way, the tap can gradually penetrate into the material [10]. This operation was also very important to define the right chamfer clearance angle of the tap that depends on the material to cut [11]. The chamfer angle helps to shear off the chips when threading a hole, and the chamfer regeneration was achieved with a helical grinding

Table 3 Operational parameters used during tapping

Operational parameters

Forming speed $[\mathrm{m} / \mathrm{min}]$

Rotation speed [rpm]

Feed rate $[\mathrm{mm} / \mathrm{rev}]$

Feed speed $[\mathrm{mm} / \mathrm{min}]$

$$
0.794
$$

Tool holder

Collet type

Clamping system
164 165 166 167 168 169 170 171 172 173 174 175 176 177 178 179 180 181 182 183 184 t3.3 $\mathrm{t} 3.4$ t3.5 $\mathrm{t} 3.6$ t3. 7 $\mathrm{t} 3.8$ 
Fig. 2 Tap characteristics and different steps in a resharpening process: (a) as-received tap, (b) tap cut in length, (c) chamfer regeneration, (d) spiral point formation

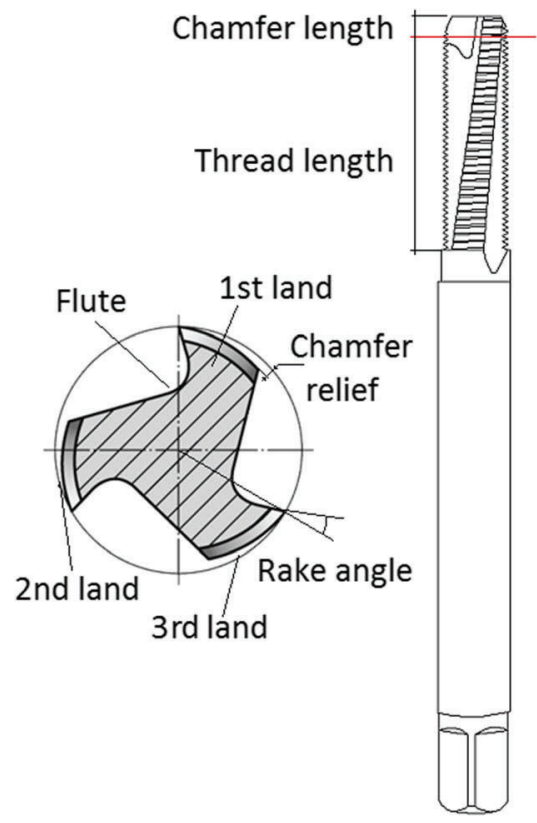

a

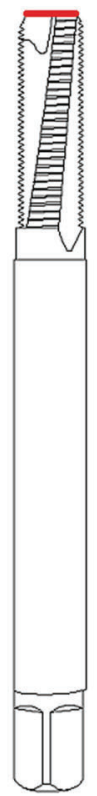

b
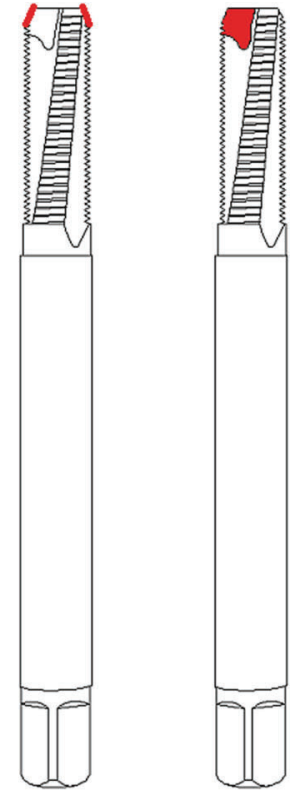

c operation, as described by Liao et al. [12]. Besides, Karpuschewski et al. [13] described a method for searching the wheel position in helical flute grinding. Finally, the third step consisted in the cutting edge reinforcement operation, see Fig. 2d, which was a grinding operation in the rake face, also called spiral point. This resharpening operation brings two aspects associated: (1) the tap exhibited a higher negative rake angle which makes the cutting edges stronger; (2) the reinforcement operation helped to finishing the cutting edges by creating new cutting edges which maximize the chamfer length of the tap.

In order to confirm that the resharpening operation was correctly performed, a Leica DCM 3D laser scanning confocal microscopy was used. This confocal microscopy allowed to record 3D topographies and also 2D profiles to analyze tool's characteristics in detail. In this sense, the as-received tap geometry was compared with respect to resharpened taps. Afterwards, surface topographies and profiles were acquired to study specific geometrical parameters of the different tested tap configurations. In particular, some of these analyzed parameters were rake angle, chamfer relief angle, radius of tool tip, and chamfer length of the tap. The measurements of the cutting edge angles were within the range of $85^{\circ}-89^{\circ}$ for both as-received and resharpened taps. The radius of the tool tip was around 20-22 $\mu \mathrm{m}$, which according to tool selection of the suppliers are appropriate for tapping with this type of tapping tool.

\subsection{Recoating process}

Some tapping tools were resharpened to extend their tool life and save expenses of tool replacement. Consequently, these tools had also been recoated with the original coating treat- 214 ment that they had in their as-received state. The aim was to 215 study the influence of the coating when comparing the tool 216 wear with respect to similar uncoated tools of this protective 217 layer. Then, a commercial TiCN coating treatment was de- 218 ployed by using the PVD method. Confocal microscopy was 219 used to ensure a reduced and homogeneous concentration of 220 droplets, an edge radius of around 20-25 $\mu \mathrm{m}$, and a layer of 221 coating thickness of about $4 \mu \mathrm{m}$. TiCN coating was chosen 222 because of being the original coating that these tools had in 223 their as-received state. This kind of coated had being widely 224 used in machining operations to enhance the cutting tool life 225 [14].

\subsection{Test stop criterion}

The test stop criterion and, subsequently, tool replacement was defined for three different circumstances. The first stop criterion is defined by the quality of the thread, which is the most common stop criterion in industry. This quality is tested by using Go/No-Go gauges. The second stop criterion was due to high values of tapping torque, particularly higher values than $12 \mathrm{Nm}$. Accordingly, high values of torque are associated with a high level of tool wear; breakages or notching in several edges of the tap; or the catastrophic failure that sometimes could happen, due to the high demands in the machining of Inconel 718. For these worn cutting edges with low cutting capabilities, undesired findings during tapping can be found, such as unremoved metal debris and notches. Finally, the third stop criterion is to analyze the wear degradation of the tapping tool in a microscope. In particular, notches of about $0.25 \mathrm{~mm}$ 
in a cutting edge of the tap are considered as a stop criterion for replacing the tapping tool.

\section{Results}

\subsection{Tool wear}

The evaluation of the cutting performance of the different tap configurations presents some difficulties, because of the low number of threaded holes that each tap can perform in this superalloy before their failure. During the tapping operation in this hard-to-cut alloy, it is common to have broken or flaked edges, which sometimes even happens during the first threaded hole. Determining the wear evolution of the cutting edges is a complex task to assess, where notches and worn edges are limiting factors in the service life and cutting capabilities of these cutting tools. Consequently, surface topographies and profiles of the different tap configurations are repetitively measured to analyze the wear evolution and surface damages. Figure 3 exhibits the cutting edges topographies and the profiles of the tool tip radius for an as-received tap and a tap resharpened once.

The surface topographies in both taps present similar geometrical dimensions, although the angle between the relief face and the rake angle changes a few degrees depending on the tap configurations. The resharpened taps present a sharper cutting edge compared with the as-received ones, as expected from the removal material process of tool resharpening. Additionally, the tool tip radius is also different between both taps. The as-received tap exhibits a radius of $20.5^{\circ}$, while the radius of the resharpened tap is about $25.5^{\circ}$. These few degrees will make a great difference during tapping, due to a higher contact area between tool-workpiece interfaces. A bigger geometrical difference is observed when comparing these two taps with a worn tap after its service life. The radius value of the worn tool tip is noticeably blunt than the as-received tap. Besides, notches and material adhesion are commonly found at the worn cutting edges. These higher values of tool tip radius and flaked cutting edges have been proved to affect the thrust force and torque during tapping $[15,16]$. Figure 4 shows an as-received tool at the end of its service life with a tool tip radius of $41^{\circ}$ and a notch in the first cylinder teeth after the chamfer clearance. Note that the tip radius is twice the value of the radius of an as-received tap. This higher value of tool tip radius increases the contact area between the interfaces of the tapping tool and the material to cut. As a consequent, higher friction coefficient is expected in tapping. This higher friction coefficient will bring higher values of cutting force and tapping torque, greater wear of the cutting tool, and poorer quality of the thread of the final workpiece.

\subsection{Cutting force and tapping torque}

In this section, axial forces and the tapping torques are analyzed for the different number of threaded holes performed in
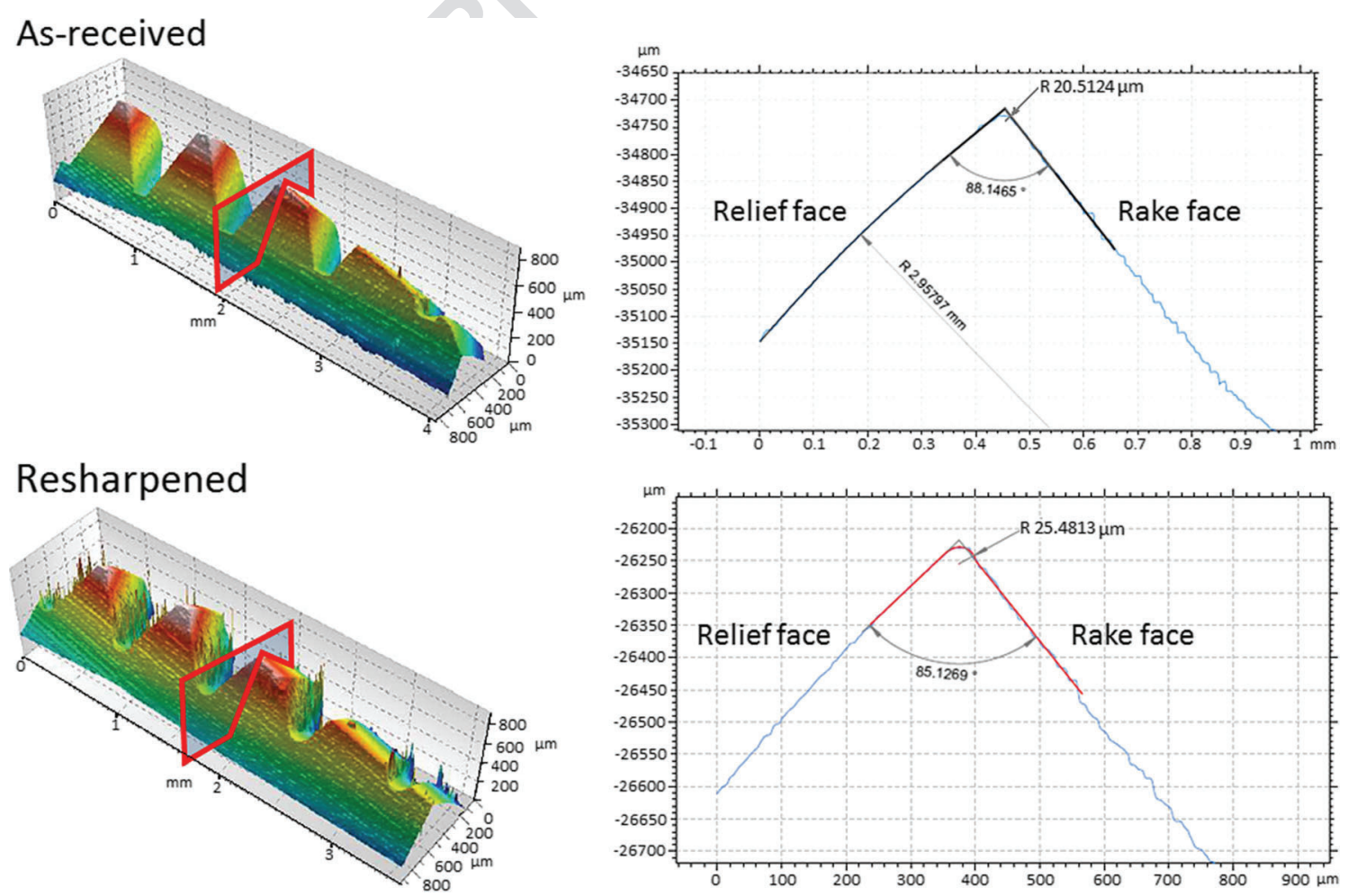

Fig. 3 Topographies of the cutting edges and tool tip radius characteristics for an as-received tap and a tap resharpened once 

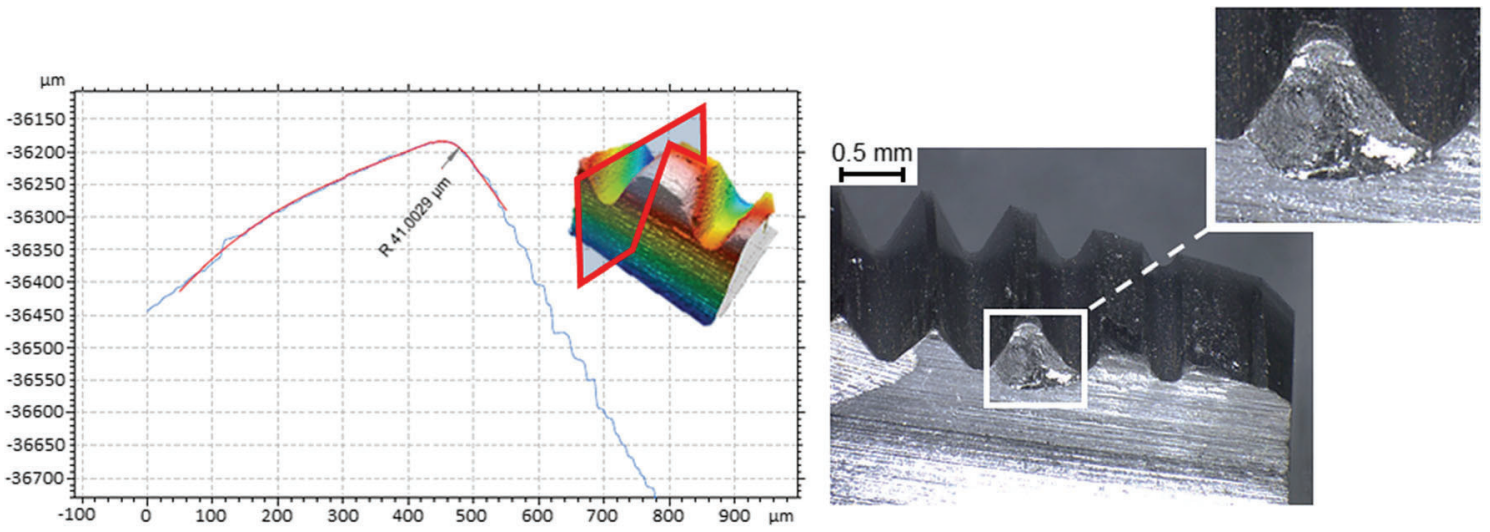

Fig. 4 Typical value of a worn cutting edge and a notch commonly found in these cutting tools at the end of its service life

Inconel 718. The magnitudes of the axial force and torque are measured to describe the cutting capabilities of each tap configurations. Thus, Fig. 5 exhibits the axial force and torque of the eight threads performed in Inconel 718 with an as-received tap, the same tap resharpened once and resharpened three times.

Firstly, it is denoted that the axial force increases with the number of threads. The 1st thread exhibits the lowest cutting forces, and the 8th thread needs a higher cutting force for tapping, independently of the tap configurations. The maximum values of axial force in 8th thread were about $-350 \mathrm{~N},-300 \mathrm{~N}$, and $-220 \mathrm{~N}$ for an as-received tap, a tap resharpened once, and a tap resharpened 3 times, respectively. Regarding the tapping torque, the maximum values of torque 8th thread were about $11.6 \mathrm{Nm}, 12 \mathrm{Nm}$, and $10 \mathrm{Nm}$ for an as-received tap, a resharpened tap, and a 3 times resharpened tap, respectively. Subsequently, the resharpened cutting tools decrease the required axial force and torque in tapping, which seems to be associated with the lower angle between the relief and rake faces. This lower angle decreases the contact area between tool and workpiece and, consequently, promotes a decrease of friction between the interfaces of the tap and the material to be threaded. Figure 6 shows the required tapping torque versus the number of threads performed in Inconel 718 with an as-received tap, a tap resharpened once, a tap resharpened and recoated, and a tap with $2^{\circ}$ extra of chamfer clearance angle. In this sense, wear capabilities of these tap configurations are analyzed according to the number of threads achieved following the same procedure. The average value of torque per thread is calculated with the area under the curves divided by the total time taken to tap the hole, rotate the tap in reverse to take them out of the hole, and clean the metal shavings from the threaded hole. Each
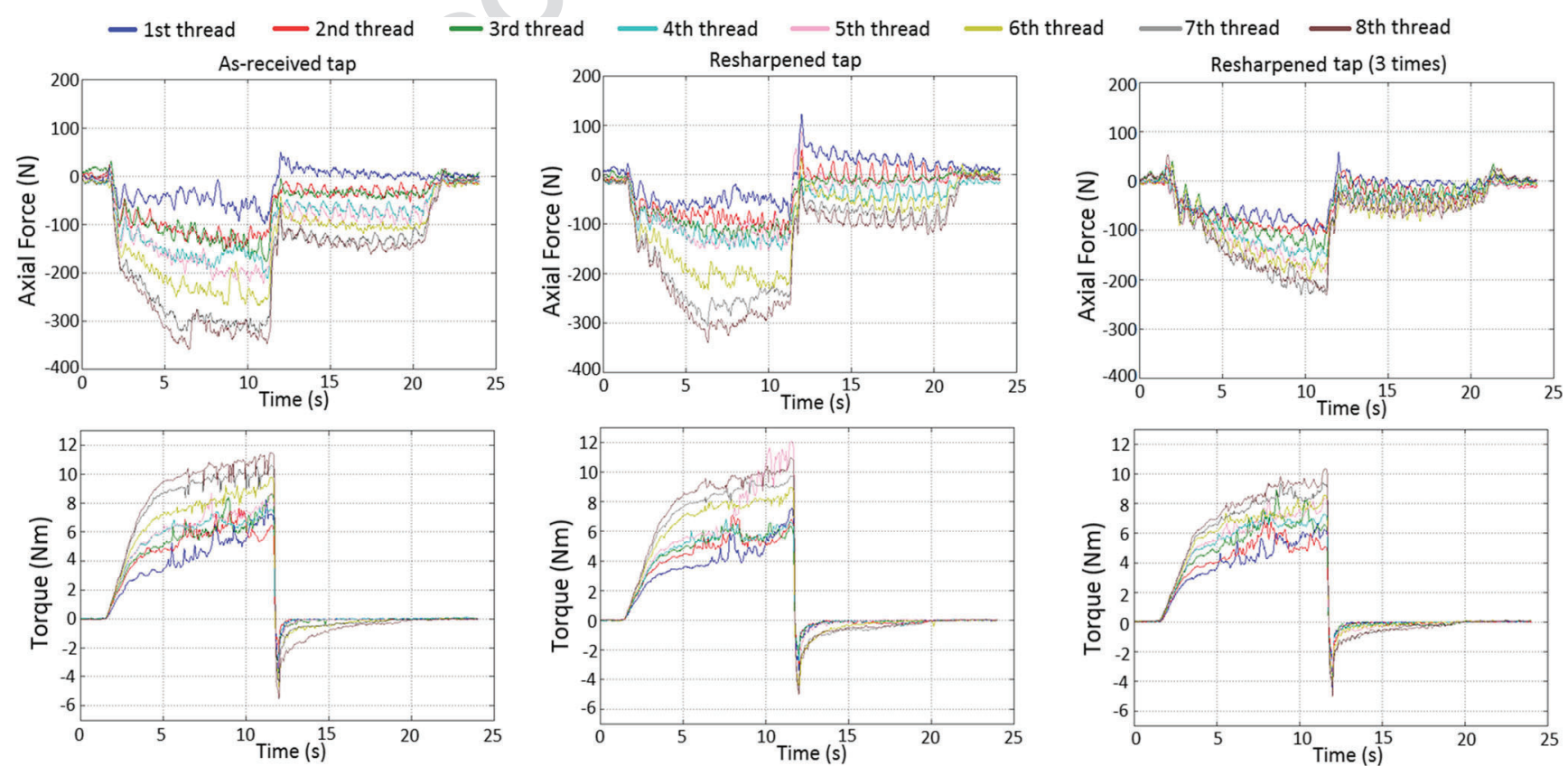

Fig. 5 Axial force and tapping torque of the different threads performed in Inconel 718 with an as-received tap, a tap resharpened once, and a tap resharpened three times 
Fig. 6 Evolution of the average torque for the tested tap configurations as a function of the number of threaded holes. Note that the average torque is represented by the average of three measurements and the error bars correspond to a standard deviation experimental value is the average of three measurements and the error bars correspond to the standard deviation. The tapping torque tends to increase with the number of threads, due to the wear of the tool that affects the cutting capabilities of the taps [17]. Accordingly, the as-received taps show the highest torque values of $2.2 \mathrm{Nm}$ and $3.2 \mathrm{Nm}$ in average for the 1 st and the 5th thread, respectively. For the last threads, the cutting tool with $2^{\circ}$ extra of chamfer clearance angle exhibits the highest torque values of 3.6 Nm and 4.8 Nm in average for the 6th and the 8th thread, respectively. On the contrary, the tap resharpened once and recoated exhibits the lowest values of torque of about $1.7 \mathrm{Nm}, 2.5 \mathrm{Nm}$, and $3.2 \mathrm{Nm}$ in average for the 1st, the 5 th, and the 8 th thread, respectively. Regarding the resharpened taps with and without recoating, they present similar torque values than the tap with $2^{\circ}$ extra of chamfer clearance angle up to the 5 th threaded hole. Similar results were reported by Lorenz et al. [18], where a reduction of torque is found for 7/16-20 UNF taps with a greater chamfer relief. Oezkaya and Biermann [19] also compared numerically and experimentally uncoated and coated tapping tools. They found lower average torque values for the coated tools independently of the metric thread. When comparing the results from the 5 th to the 8 th threaded holes, noticeable torque differences are found between the resharpened taps with respect to the resharpened and recoated taps. In particular, lower torque values are observed for the recoated taps, due to the excellent wear capabilities of TiCN which helps to enhance the service life by reducing tool wear. Finally, the worst scenario is found for the tap with $2^{\circ}$ extra of chamfer clearance with values of torque of $4.8 \mathrm{Nm}$, when performing the 8 th threaded hole. This high value of torque is likely attributed to the higher surface degradation observed in the first cylinder teeth after the chamfer clearance modification, as can be seen in the surface integrity subsection.

\subsection{Surface integrity}

The surface analysis of the different tested taps is carried out after performing different number of threaded holes (from one to eight threads). For this purpose, the threaded samples were cut from the end part and encapsulated in Bakelite. After that, they were grinded with a series of grits in a rotating wheel, polished by using several cloths with diamond suspensions spray up to $1 \mu \mathrm{m}$ and etched with Kalling's reagent $\mathrm{n}^{\circ} 2$ ( $5 \mathrm{~g} \mathrm{CuCl}_{2}, 100 \mathrm{ml} \mathrm{HCl}, 100 \mathrm{ml}$ ethanol). Then, the material's microstructure was analyzed as recommended by the ASTM standard E407 [20]. Following this procedure, the edges of the cutting tools are observed with the aim to describe surface damage, material adhesion, microcracks, laminations' effects, and worn of the tool tip radius. These undesired findings are aggravated right at the end of the chamfer length, which defines the finished size of the desired thread. All these surface defects will affect the quality and lifespan of these tapping tools. Sometimes microcracks, material adhesion and lamination can be found in the first threaded hole, even for threads generated with a brand new cutting tap. Figure 7a shows the surface integrity of the specimens threaded with an asreceived tap in the $1 \mathrm{st}, 5 \mathrm{th}$, and 8 th threaded hole. Additionally, Fig. 7b exhibits the surface deviation after performing the 8 th threaded hole compared with respect to the as-received tap. An evident worn progression of $180 \mu \mathrm{m}$ is denoted at the tool crest after performing the 8th threaded hole.

No noticeable surface differences are found at the tool crests and valleys of the taps between the 1st and 5 th thread. Similar results were found when comparing equivalent threads for as-received and resharpened taps. Evidences of worn of tool tip radius or the threaded material are denoted in the 8th threaded hole. In particular, flatted edges with higher radius are found, but not micro cracks, material adhesion, or deformed grains. Higher tool tip degradation and cutting 
Fig. 7 (a) Surface integrity of a tapping hole with an as-received tap in the 1 st, 5 th, and 8 th threaded hole. (b) Worn progression tool tip radius and surface damage at the valley after performing the 8th tapping hole with respect the as-received tap

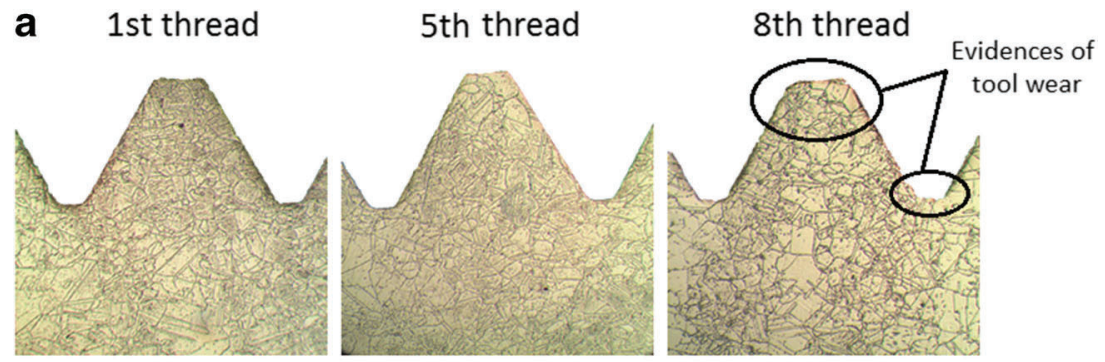

b

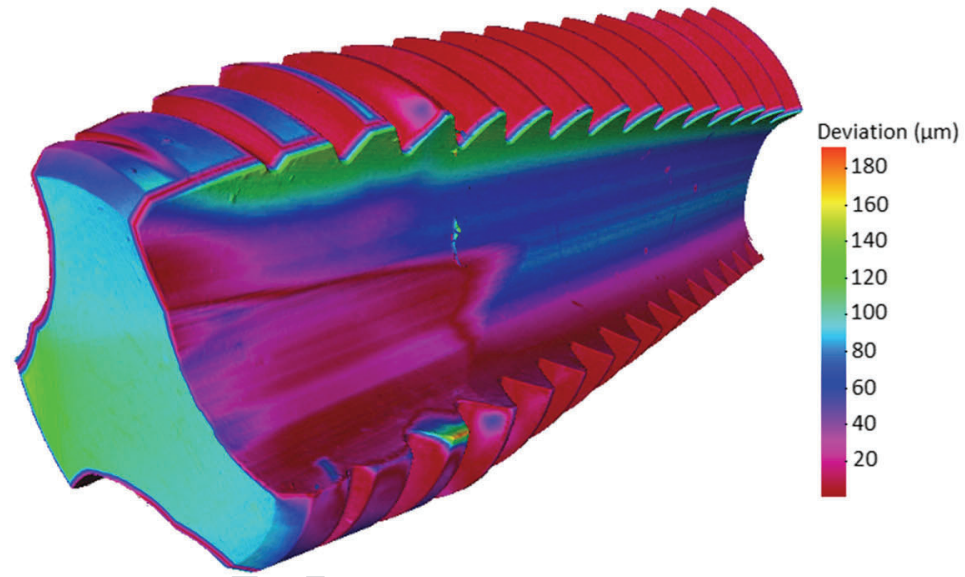

forces were found in the crest of the first full thread of the cutting tool, right after the chamfer length, which is referred to a maximum load distribution across the cutting teeth and chip formation. Similar results were described by Axinte et al. [21] when investigating the surface integrity of different polished methods in Ti6AL4V. Figure 8 shows the profiles of the cutting edges for an as-received tap, an as-received tap in the 8th thread, and a resharpened tap without coating in the 8th thread. The profile measurement is performed at the first full thread, where higher tool degradation is observed. Resulting that the radius of the tool tip for an as-received tap is around 2.5 time sharper than the same tool after performing 8th threaded holes. Also, the radius of the tool tip for an as- received tap is around 7 times sharper than a resharpened tool, both after achieving the 8 th thread. Note that the resharpening process is performed to the worn cutting edge to achieve similar tool tip radius and rake angle than the as-received tap (see Fig. 3). In this sense, it is expected to weaken the cutting edges due to the rake angle decrease with the resharpening process.

Despite of the roundness differences at the tool tip radius, all the threads were correctly assessed without deformed grains, cracks, or material adhesion in the threaded holes, independently of the tap configurations. Regarding the surface deviation of the cutting tool when performing the 8 th threaded hole, crest edge smoothness evidences up to $25 \mu \mathrm{m}$ are denoted right at the end of the chamber length, particularly at the
411
Fig. 8 2D profiles of the cutting edge for an as-received tap, an asreceived tap after the 8 th thread, and a resharpened tap after the 8th thread

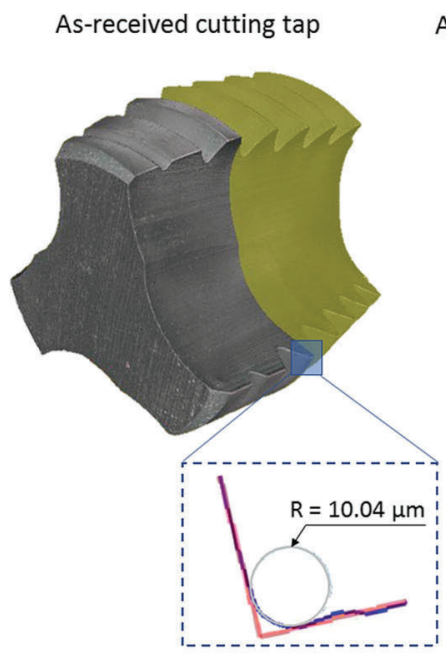

As-received tap after the 8th thread

Resharpened after the 8th thread

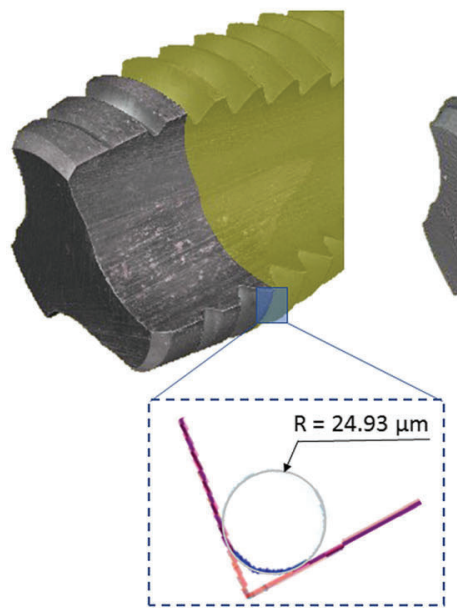

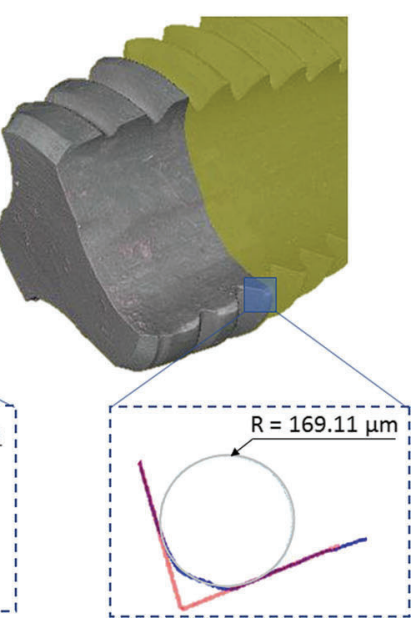


first full-thread teeth. In this first full thread is expected to bear the higher cutting force [22]. The resharpened and uncoated taps showed higher radius of the tool tip after the tapping process, which is associated to higher cutting force deviation and worse quality of the surface integrity. Furthermore, the surface deviation in average is found to be $180 \mu \mathrm{m}$ along the tap's flute (see Fig. 7b), due to the interaction between the cutting tool with the metal shavings. Similar values of wear of the as-received tap are found for resharpened and recoated taps. This is because recoating the helical flute facilitate firstly to remove the metal chips and secondly to reach the lubricant the cutting teeth. Therefore, resharpening and recoating taps have shown the best machining performance in tapping Inconel 718 , because of reducing adhesion which was the main wear mechanism. Hence, resharpening and recoating taps could be the right choice for improving the tapping operation and saving expenses of tool replacement and manufacturing downtime.

\section{Conclusions}

In this research, tapping capabilities are explored through monitoring different tap configurations, according to the number of threaded holes in a common aeronautical alloy. Therefore, the main conclusions can be summarized as the following:

- The cutting performance of as-received, resharpened, recoated, and modified chamber clearance taps are studied for threading holes in Inconel 718. Accordingly, resharpened taps have been denoted to be an alternative way instead of using new taps in order to achieve suitable threads and to save costs. Particularly, lower axial force, tapping torque, and wear rate are examined when the resharpened taps are also recoated compared to the asreceived taps.

- Monitoring the cutting forces and torque during the tapping process help us to detect the failure of the tap and, consequently, avoid the extraction a broken tap from a high added value end part. In the 1 st threaded hole, the as-received tap exhibited the highest value of torque, compared to the rest of tap configurations. On the contrary, the tap with a chamfer clearance modification exhibited the highest value of torque for the 8 th threaded hole. The resharpened and recoated tap showed the lowest values of torque for the $1 \mathrm{st}$ and the 8 th threaded hole. Consequently, resharpening is an effective operation in spite of extending the service life of the tapping tools.

- Tap configuration and coating layer play a key role in metal cutting of this nickel-based superalloy with low machinability. Greater tool degradation is denoted in the first threaded hole, where metal chipping, notches, or worn cutting edges are examined independently of the tap configuration. Therefore, monitoring the tapping torque and the edge roundness progression is crucial in order to have an accurate thread tolerance, achieve the desired surface integrity, and prevent tool fracture.

Acknowledgments The authors would like to thank to ITP Aero S.A. for the information and the material contribution to this work. We are also grateful to the University of the Basque Country and the Aeronautics Advanced Manufacturing Center (CFAA) of Bilbao for permitting the usage of the facilities and devices required to accomplish this work.

Funding information This work has been funded by the project INNPACTO and by the Serra Húnter program (Generalitat de Catalunya) reference number UPC-LE-304 (2018).

\section{References}

1. Ehmann KF, De Vries MF (1990) Grinding wheel profile definition for the manufacture of drill flutes. CIRP Ann Manuf Technol 39(1): 153-156. https://doi.org/10.1016/S0007-8506(07)61024-5

2. Uhlmann E, Hbert C (2011) Tool grinding of end mill cutting tools made from high performance ceramics and cemented carbides. CIRP Ann Manuf Technol 60(1):359-362. https://doi.org/10. 1016/j.cirp.2011.03.106

3. Ko SL (1994) Geometrical analysis of helical flute grinding and application to end mill. Trans NAMRI/SME 12:165-172 ISBN: 0872634507

4. Sanchez Egea AJ, Martynenko V, Martnez Krahmer D, Lopez de Lacalle LN, Benitez A, Genovese G (2018) On the cutting performance of segmented diamond blades when dry- cutting concrete. Materials 11(264):1-12. https://doi.org/10.3390/ma11020264

5. Belluco W, De Chiffre L (2002) Surface integrity and part accuracy in reaming and tapping stainless steel with new vegetable based cutting oils. Tribol Int 35(12):865-870. https://doi.org/10.1016/ S0301-679X(02)00093-2

6. Armarego EJA, Chen MNP (2002) Predictive cutting models for the forces and torque in machine tapping with straight flute taps. CIRP Ann - Manuf Technol 51(1):75-78. https://doi.org/10.1016/ S0007-8506(07)61469-3

7. Fernandez-Abia AI, Barreiro J, Fernandez-Larrinoa J, Lopez de Lacalle LN, Fernandez-Valdivielso A, Pereira OM (2013) Behaviour of PVD coatings in the turning of austenitic stainless steels. Procedia Eng 63:133-141. https://doi.org/10.1016/j.proeng. 2013.08.241

8. Reiter AE, Brunner B, Ante M, Rechberger J (2006) Investigation of several PVD coatings for blind hole tapping in austenitic stainless steel. Surf Coat Technol 200(18-19):5532-5541. https://doi. org/10.1016/j.surfcoat.2005.07.100

9. ASME B1.1-2003, Unified Inch Screw Threads (UN and UNR Thread Form), The American Society of Mechanical Engineers

10. Kaldor S, Trendler PHH, Hodgson T, Micheletti GF (1994) Investigations into the clearance geometry of end mills. CIRP Ann Manuf Technol 33(1):33-38. https://doi.org/10.1016/S00078506(07)61374-2

11. Kim YH, Ko SL (2002) Development of design and manufacturing technology for end mills in machining hardened steel. J Mater Process Technol 130/131:653-661. https://doi.org/10.1016/S09240136(02)00728-8

12. Liao YS, Chen CCA, Chao CL, Tso PL (2010) Research on a helical drill point grinding machine. Adv Mater Res 126/128: 
791-795. https://doi.org/10.4028/www.scientific.net/AMR.126128.791

13. Karpuschewski B (2011) Automatic search for wheel position in flute grinding of cutting tools. CIRP Ann Manuf Technol 60(1): 347-350. https://doi.org/10.1016/j.cirp.2011.03.113

14. Rodríguez-Barrero S, Fernández-Larrinoa J, Azkona I, López de Lacalle LN, Polvorosa R (2016) Enhanced performance of nanostructured coatings for drilling by droplet elimination. Mater Manuf Process 31(5):593-602. https://doi.org/10.1080/10426914.2014. 973582

15. Bezerra AA, Coelho RT (2008) Tool wear aspects when applying high-speed tapping on grey cast iron. Proc Inst Mech Eng B J Eng Manuf 222(2):129-136. https://doi.org/10.1243/09544054JEM914

16. Narayanan SN, Raviraja A Performance Evaluation of Machine Tap for tapping Al6061-T6 Aluminium Alloy. 6th International Conference on Electronics, Computer and Manufacturing Engineering 2017; 250-254. https://doi.org/10.17758/EAP. U0317109

17. Biermann D, Oezkaya E (2017) CFD simulation for internal coolant channel design of tapping tools to reduce tool wear. CIRP Ann 66(1):109-112. https://doi.org/10.1016/j.cirp.2017.04.024
18. Lorenz G (1980) On tapping torque and tap geometry. CIRP Ann 29(1):1-4. https://doi.org/10.1016/S0007-8506(07)61284-0

19. Oezkaya E, Biermann D (2018) Development of a geometrical 554 torque prediction method (GTPM) to automatically determine the 555 relative torque for different tapping tools and diameters. Int J Adv 556 Manuf Technol 97:1465-1479. https://doi.org/10.1007/s00170- 557 018-2037-3

20. ASTM E407-2007. Standard practice for microetching metals and 559 alloys, American Society for Testing and Materials $\quad 560$

21. Axinte DA, Kwong J, Kong MC (2009) Workpiece surface integ- 561 rity of Ti-6-4 heat-resistant alloy when employing different 562 polishing methods. J Mater Process Technol 209(4):1843-1852. 563 https://doi.org/10.1016/j.jmatprotec.2008.04.046 564

22. Gil-Del-Val AA, Diguez PM, Arizmendi M, Estrems M (2015) 565 Experimental study of tapping wear mechanisms on nodular cast 566 iron. Procedia Eng 132:190-196. https://doi.org/10.1016/j.proeng. 567 2015.12.469

Publisher's note Springer Nature remains neutral with regard to jurisdic- $\quad 569$ tional claims in published maps and institutional affiliations. 